\title{
Food Reduction Adds Stress to Chronic Silver Nanoparticle Toxicity for Daphnia magna
}

\author{
Yvonne Sakka $^{1 *}$, Alexander Völkel ${ }^{1,2}$ and Juliane Filser ${ }^{1}$ \\ ${ }^{1}$ University of Bremen, Center for Environmental Research and Technology, General and Theoretical Ecology, Leobener Str. 28359 Bremen, Germany \\ ${ }^{2}$ Sanofi-Aventis Deutschland GmbH, Industriepark Höchst, Gebäude H500, 65926 Frankfurt am Main, Germany
}

Received: September 5, 2016; Accepted: October 17, 2016; Published: October 21, 2016

*Corresponding author: Yvonne Sakka, University of Bremen, Center for Environmental Research and Technology, General and Theoretical Ecology, Leobener Str. 28359 Bremen, Germany, E-mail: yvonne.sakka@uni-bremen.de

\begin{abstract}
Chronic toxicity of silver nanoparticles (AgNP) to Daphnia magna has received increasing attention in research, also with regard to influencing factors such as coating or feeding regime. With regard to the later, only the effect of increasing food quantities has been tested up to now. In the present study, we investigated whether a decrease in food quantity causes increasing toxicity; as suggested by the results in the above-mentioned study. For this purpose, a chronic test using the reference material $\mathrm{NM}-300 \mathrm{~K}$ at increasing concentrations up to $6.6 \mu \mathrm{g} \mathrm{Ag} \mathrm{L}{ }^{-1}$ and three different food levels was conducted.

The moderate decrease in food quantity $75 \%$ of standard food level) caused comparable toxicity results compared to the standard food level, while the intense decrease ( $50 \%$ of standard food) caused a clear increase in toxicity. However, the extent of this increase varied with the investigated endpoint of the chronic test and some endpoints did not vary between food levels at all. Number of clutches and onset of reproduction showed the clearest response in terms of decreasing Lowest-Observed-Effect-Concentrations (from $>6.6$ to

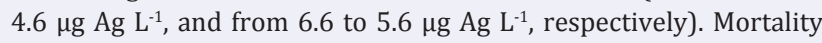
showed the highest change in terms of relative increase: at the highest AgNP concentration, mortality increased from $40 \%$ in the standard food treatment to $90 \%$ at $50 \%$ food level. Even though this may raise concern about risk assessment of AgNP using standard food conditions, the high similarity in concentration dependence between most endpoints indicates that the chronic Daphnia test is protective despite the use of unnaturally high food supply.
\end{abstract}

Keywords: Food limitation; Silver nanoparticles; Daphnia magna; Chronic

\section{Introduction}

Silver nanoparticles (AgNP) are used in various consumer products which are mostly related to sports and health uses [1]. For many of those products, for example textiles, washing are an inevitable task during the product life cycle and may cause the release of silver nanoparticles as well as silver ions. Some studies have addressed the amount and type of the released silver from textiles into the wastewater system, as well as their fate during the wastewater treatment process [2-5]. In most cases, releases have been reported to be at very low levels under standard washing conditions and include varying amounts of particles in the range of "nano"(= smaller than $100 \mathrm{~nm})[2,3]$. The amounts and sizes of the released AgNP as well as their fate are highly influenced by the identity of the washed product and the washing conditions chosen [2,6]. However, a constant release of low doses of AgNP can be assumed for a simplified experimental design.

Despite these results, most experimental studies on AgNP ecotoxicity have used acute tests with high doses compared to estimated environmental conditions [7], and results of chronic toxicity studies or mesocosm experiments are just emerging [8]. For the commonly used aquatic test organism Daphnia magna, concentrations causing negative effects during chronic exposure range from about one to more than one hundred $\mu \mathrm{gg} \mathrm{L}^{-1}$ [916]. Predicted environmental concentrations are mainly in the range of ng L ${ }^{-1}$ [4]. Thus, long-term exposure of AgNP may only be critical in case of additional factors which increase effects of AgNP.

For short-term experiments with AgNP, it has been shown that exposure conditions strongly affect AgNP behavior and toxicity $[8,12,17]$. An important difference between acute and chronic toxicity tests with $D$. magna is the presence of food. Food in terms of algae has been shown to reduce acute toxicity of AgNP $[9,12,13]$, but also to represent one of the main uptake routes of AgNP [16]. In addition, Lam, et al. [18] showed that dietary assimilation of silver was much higher at low than at high food concentrations, which may be also the case for AgNP.

Besides affecting the toxicity of AgNP, algae as food directly affect the population growth of daphnids; a relation which has been intensely studied and modeled [19-25]. Increasing food quantity was well-related to increased individual size as well as population growth in the laboratory [26-28], and in the field [2931]. This relation has also been confirmed by modeling of data [32-34].

Algae in tests with D. magna may thus have two different functions: serving as energy resource (food) and as "carrier"of AgNP into the test organism. To our knowledge, only one study addressed the effect of food availability on AgNP toxicity [11]. In this study, 3-fold elevation of food quantity reduced the 
toxicity of citrate coated AgNP in terms of mortality, growth and reproduction compared to the standard food level. In the present study, we addressed whether we can find a similar pattern for the relation between food quantity and AgNP toxicity using decreasing food levels and a differently stabilized AgNP. The later is also of interest in the context of environmental hazard of AgNP: if the decreasing food levels increases AgNP toxicity, it may be possible that Lowest-Observed-Effect-Concentrations (LOECs) reach estimated environmental concentrations.

To investigate the relation between AgNP exposure and food decrease, a full-factorial design with three different food levels and five AgNP concentrations was used. Based on the assumption of food being an important energy resource and a reduced uptake of silver at higher food quantities, we expected higher growth, as well as reproduction when more food is provided. In addition, we expected the lowest mortality to occur at standard food conditions. And based on other chronic results [9-11,13,14] we expected growth and mortality to be the most sensitive endpoints at all food conditions.

\section{Materials and Methods}

\section{Test chemicals}

Silver Nanoparticles were purchased from ras materials $\mathrm{GmbH}$ (Regensburg, Germany; reference material NM-300K). AgNP were of spherical shape and a mean size of $20 \mathrm{~nm}$ according to the producer information. They were delivered as $10.16 \% \mathrm{wt}$ silver in a dispersion containing $4 \%$ polyoxyethylene sorbitan monolaurate, (TWEEN 20) and polyoxyethylene glycerole trioleate (trade name TAGAT ${ }^{\circledR}$ TO [35]) each. Prior to use, the delivered dispersion was diluted to a silver content of $2 \%$ wt with Milli-Q-water (Millipore, Merck KgaA, Darmstadt, Germany), sonicated for $15 \mathrm{~min}$ in a water bath (Sonorex, RE100H, Bandelin electronic GmbH \& Co KG, Berlin, Germany), and used to prepare a stock dispersion in the test medium, Elendt M7, with a nominal silver concentration of $10 \mathrm{mg} \mathrm{Ag} \mathrm{L}^{-1}$. The medium stock dispersion was stored in the dark at $4^{\circ} \mathrm{C}$ for $7 \mathrm{~d}$ prior to the start of the experiment and used throughout the experiment to prepare the test dispersions.

Stability and mean particle size during the chronic test were measured in a pilot test with two beakers of stock dispersion and the same temperature, test volume and illumination, but without algae or Daphnia. Measurements were done every $24 \mathrm{~h}$ by absorption analysis (Cadas200 Spektral photometer, HACH LANGE GmbH, Berlin, Germany) and Dynamic Light Scattering
(DLS) and (Delsa Nano C, Beckmann Coulter Inc., Brea, USA) with 10 repetitions in case of DLS and 6 in case of zeta-potential measurements. Results of both beakers were pooled after measurement to reduce scatter between samples. One sample of the stock dispersion was measured again prior to the start of the test to assure similar starting conditions.

\section{Test organisms}

The green algae Pseudokirchneriella subcapitata (strain no. 61.81, from the Culture Collection of Algae SAG, Göttingen, Germany) was used for feeding. Algae were cultured using a green algae medium (see Supporting Information, SI Table 1) and permanent light at $20^{\circ} \mathrm{C}$. Based on the assumption that one algae corresponds to an average of $1.59 * 10^{-8} \mathrm{mg} \mathrm{C}, D$. magna cultures were fed $0.15 \mathrm{mg}$ C Daphnia ${ }^{-1} \mathrm{~d}^{-1}$ with every media exchange twice a week.

D. magna originated from Bayer GmbH (Monheim, Germany) and were cultured in our laboratory for several years after obtaining them from the Center for Environmental Research (UFZ; Leipzig, Germany). D. magna were cultured at $20 \pm 1{ }^{\circ} \mathrm{C}$ using a 16:8 h light-dark cycle and a density of 20 animals $\mathrm{L}^{-1}$. Cultures were considered suitable for testing after their third brood when reproduction was high and no mortality occurred in the cultures.

\section{Chronic Daphnia Test}

The chronic Daphnia test was conducted according to OECD guideline 211 [36], using 10 replicates per concentration, $20 \pm 1$ ${ }^{\circ} \mathrm{C}$, and a 16:8 h light-dark cycle. A linear equation was used to calculate the optimal amount of food throughout the test (mg C $=0.0057 * d+0.008$; with $d=$ median day of the media exchange period). Food was added with every media exchange, every 2 to 3 days. To assess the effect of food reduction, three quarters and half of the calculated optimal amount of food were used. The three different food regimes (100 \%, $75 \%, 50 \%)$ were applied in a full-factorial design with four concentrations $(5,9,11,13 \mu \mathrm{g} \mathrm{Ag}$ $\mathrm{L}^{-1}$ ) and a control. Survival and reproduction was controlled daily, number of molts with every media exchange. At the end of the test, animals were fixed with formaldehyde at a final concentration of $1.5 \%$ (v/ v). Body length was measured using picture analysis and a stereomicroscope (Olympus SZX-ILLB200, Optical Co. LTD, Ritto, Japan) connected camera (MCA-1000, Müller Optronic $\mathrm{GmbH}$, Erfurt, Germany). Analyzed endpoints were reproduction (including cumulative number of neonates, day and number of neonates at first reproduction, cumulative number of clutches,

Table 1: Results of the particle characterization during the pilot test and before the start of the chronic test in Elendt M7 medium at a concentration of $10 \mathrm{mg} \mathrm{Ag} \mathrm{L}^{-1}$, All values are given as mean values with standard errors $\left({ }^{\mathrm{a}} \mathrm{n}=20,{ }^{\mathrm{b}} \mathrm{n}=9,{ }^{\mathrm{c}} \mathrm{n}=12,{ }^{\mathrm{d}} \mathrm{n}=3\right)$.

\begin{tabular}{|c|c|c|c|c|c|c|}
\hline Experiment & Day & $\begin{array}{l}\text { Cumulative HDD } \\
\text { [nm] }\end{array}$ & $\begin{array}{l}\text { Peak HDD } \\
{[\mathrm{nm}]}\end{array}$ & $\begin{array}{l}\text { Polydispersity Index } \\
\text { (PDI) }\end{array}$ & $\begin{array}{l}\text { Zeta-potential } \\
{[\mathrm{mV}]}\end{array}$ & $\begin{array}{l}\text { Conductivity } \\
{\left[\mathrm{mS} \mathrm{cm}^{-1}\right]}\end{array}$ \\
\hline \multirow[t]{2}{*}{ Pilot test } & 0 & $150 \pm 27^{a}$ & $55 \pm 2^{\mathrm{a}}$ & $0.21 \pm 0.02^{\mathrm{a}}$ & $-11.1 \pm 0.6^{c}$ & $0.737 \pm 0.002^{c}$ \\
\hline & 3 & $469 \pm 27^{a}$ & $69 \pm 3^{a}$ & $0.22 \pm 0.01^{\mathrm{a}}$ & $-12.4 \pm 0.4^{c}$ & $0.852 \pm 0.002^{c}$ \\
\hline Chronic test & 0 & $381 \pm 66^{b}$ & $44 \pm 2^{\mathrm{b}}$ & NA & $-16.4 \pm 0.4^{\mathrm{d}}$ & $0.718 \pm 0.001^{\mathrm{d}}$ \\
\hline
\end{tabular}

HDD: Hydrodynamic Peak Diameter 
and mean number of neonates per clutch), cumulative number of molts, body length and survival.

To obtain actual values for carbon content of the algae used for feeding during the chronic test, carbon content was measured prior to feeding with every media exchange: First, the algae were centrifuged for $10 \mathrm{~min}$ at $4480 \mathrm{rpm}$ (3-18K, Sigma, Osterode, Germany) and re-suspended in carbon-free algae medium (SI Table 1). The re-suspended algae were counted with a cell counting chamber (Neubauer, Marienfeld GmbH \& Co KG, LaudaKönigshofen, Germany) and their carbon content was analyzed by laser driven $\mathrm{CO}_{2}$ detection (C-mat 5500 , Ströhlein Instruments, Germany) after combustion (I-05/ RP and D-03GTE, Ströhlein Instruments, Germany). The corresponding carbon content per alga was then calculated and the algae culture stored in the dark at $4^{\circ} \mathrm{C}$ for use the following day.

Actual silver concentrations in the test dispersions were measured at the beginning and the end of every media exchange. For this, $100 \mu \mathrm{L}$ of test dispersion were acidified with $1 \% \mathrm{HNO}_{3}$ and stored in the dark. The highest concentration of each food regime was measured using graphite furnace atomic adsorption spectrometry (GF 90 and Solaar 989QZ, Unicam, Cambridge, UK). After measurement, time weighted mean was calculated for each food level in the measured concentration as described in the guideline (OECD, 1998). The proportional relation between time weighted mean and nominal concentration was used to calculate actual concentrations of all other concentrations.

For estimating differences in silver uptake, 3 animals of each food level were also measured by graphite furnace atomic adsorption spectrometry and silver body burden in relation to weight after fixation was calculated. This analysis was only done at $11 \mu \mathrm{g} \mathrm{Ag} \mathrm{L}^{-1}$ due to the detection limit of the device (about $0.03 \mu \mathrm{g} \mathrm{Ag} \mathrm{g}^{-1}$ ) and the limited number of surviving animals at higher concentrations. Prior to silver body burden measurements, fixed animals were digested first in $0.1 \mathrm{M} \mathrm{NaOH}$ for $2 \mathrm{~h}$, then in a mixture of $\mathrm{HCl}_{\text {conc }}$ and $\mathrm{HNO}_{3 \text { conc. }}(3: 1)$ for additional $2 \mathrm{~h}$. Both digestion steps were made in a water bath at $65^{\circ} \mathrm{C}$.

\section{Data Analysis}

Each endpoint of the chronic test was analyzed separately using R version 3.1.2 [37], In no case homogeneity of variance could be observed or reached after transformation when both silver concentration and food level were used, so the data were split according to food levels and to silver concentration and analyzed separately. Details on transformations and used models are listed in the Supporting Information (SI, Tables S1S7). For all endpoints and all datasets, Levene's test was used to analyze homogeneity of variance and if this criterion was met, linear models were applied to datasets using silver concentration or food level as only explanatory variable, and one-factorial ANOVAs with post-hoc analysis (Tukey's test) were used to determine of Lowest-Observed-Effect-Concentration (LOEC) and No-Observed-Effect-Concentration (NOEC) values or reveal significant differences between food levels. In case homogeneity of variance was not given, transformations were applied to the data (square-root or boxcox) and the test was repeated. If the data did still not show homogeneity of variance, Kruskal-Wallis tests with post-hoc analysis (multiple comparisons of means for Kruskal-Wallis tests, package pgirmess) were made. All linear models and ANOVAs were checked for normality of errors using a Shapiro-Wilk test.

\section{Results}

\section{Food influences}

The reduction of food did not cause significant effects when the food level was reduced to $75 \%$ (Supporting Information (SI), Table S8). When it was reduced to $50 \%$ of the standard food, the reproduction in terms of cumulative number of neonates and mean number of neonates per clutch decreased significantly ( $p$ $<0.001$, Kruskal-Wallis test; for both endpoints, SI, Table S8). Number of clutches and onset of reproduction did not respond to changes in the food regime ( $p=0.352$ and $p=0.945$, respectively; Kruskal-Wallis tests for both endpoints). The body length at the end of the test was also significantly smaller in the $50 \%$ food treatment compared to the other two food regimes $(6.0 \pm 0.1 \mathrm{~mm}$ vs. $6.7 \pm 0.1 \mathrm{~mm}$ at $75 \%$ food and $6.8 \pm 0.1 \mathrm{~mm}$ at $100 \%$ food). Mortality was zero in all control treatments (Table 3 ).

\section{Particle characterization}

Results of the particle characterization of all measurements are summarized in Table 1. Cumulative Hydrodynamic Diameter (cumulative HDD) and peak HDD increased throughout the pilot test $(150 \pm 27 \mathrm{~nm}$ to $469 \pm 27 \mathrm{~nm}$ and: $55 \pm 2 \mathrm{~nm}$ to $69 \pm 3 \mathrm{~nm}$, respectively), while the polydispersity index was similar in all three measurements (about 0.2). The surface potential ranged between -16 and $-11 \mathrm{mV}$ with a conductivity of 0.74 and $0.85 \mathrm{mS}$ $\mathrm{cm}^{-1}$.

The results for the stock dispersion used for the chronic test were similar to the results of the pilot test: The peak HDD was slightly lower in the chronic test stock dispersion than in the pilot test on day 0 while the cumulative HDD was higher than in the pilot test, but in the range of all later measurements of cumulative HDD values in the pilot test (Table 1). The surface potential and the conductivity were also similar to the range measured during the pilot test $\left(16.4 \pm 0.4 \mathrm{mV}\right.$ at $\left.0.718 \pm 0.001 \mathrm{mS} \mathrm{cm}^{-1}\right)$.

\section{Analytical results}

The measurement of actual silver concentrations in the highest nominal silver concentration resulted in similar timeweighted mean values for all food treatments, with differences in the range of calculation and measurement uncertainty. For reasons of simplicity, one pooled time-weighted mean value was used ( $6.6 \mu \mathrm{g} \mathrm{Ag} \mathrm{L}^{-1}$ at the nominal concentration of $13 \mu \mathrm{g} \mathrm{Ag}$ $\mathrm{L}^{-1}$ ). The relative decrease between nominal concentration and time-weighted mean was about $51 \%$. This value was used for the calculation of all other time-weighted mean concentrations, resulting in 2.5 ; 4.6 ; 5.6 ; $6.6 \mu \mathrm{g} \mathrm{Ag} \mathrm{L}^{-1}$ as actual concentrations, corresponding to nominal concentrations of 5; 9; 11; $13 \mu \mathrm{g} \mathrm{Ag} \mathrm{L}^{-1}$, respectively. These calculated actual concentrations were used for all data analyses in the current study.

The measurement of silver body burden of a subsample of 


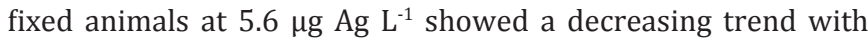
increasing food quantities, but differences between mean silver body burden in all food treatments were not significant ( $p=$ 0.088, ANOVA). The mean silver body burdens were as follows: $100 \%$ food $=0.8 \pm 0.2 \mu \mathrm{g} \mathrm{Ag} \mathrm{g}^{-1}{ }_{\text {wetweight }} ; 5 \%$ food $=2.7 \pm 0.2 \mu \mathrm{g} \mathrm{Ag}$ $\mathrm{g}^{-1}{ }_{\text {wetweight }} ; 50 \%=2.3 \pm 0.9 \mu \mathrm{g} \mathrm{Ag} \mathrm{g}^{-1}{ }_{\text {wetweight }}$

\section{Chronic AgNP toxicity}

In the standard food level treatment, AgNP significantly reduced the reproduction in terms of cumulative number of neonates ( $p=0.025$, linear model) total number of clutches ( $p=$ 0.025 , Kruskal-Wallis test), and onset of reproduction $(p<0.001$, Kruskal-Wallis test, Figure 1). However, a LOEC could only be determined for onset of reproduction (Table 2).

Molting was also significantly reduced by AgNP exposure ( $p=$ 0.007 , linear model; Figure 2b), but no significant difference could be detected between single concentrations. Mortality increased with increasing AgNP concentration up to $40 \%$ in the highest AgNP concentration (Tables $2+3$ ). Body length was not reduced, but was significantly higher in the lowest AgNP concentration $\left(2.5 \mu \mathrm{g} \mathrm{Ag} \mathrm{L}^{-1}\right)$ than in all higher concentrations $(p<0.05$, KruskalWallis post-hoc analysis; Table 2, Figure 2a).

Summarized, the most sensitive endpoints according to LOEC values were onset of reproduction and mortality. The relative decrease was $40 \%$ for mortality and about $17 \%$ for onset of

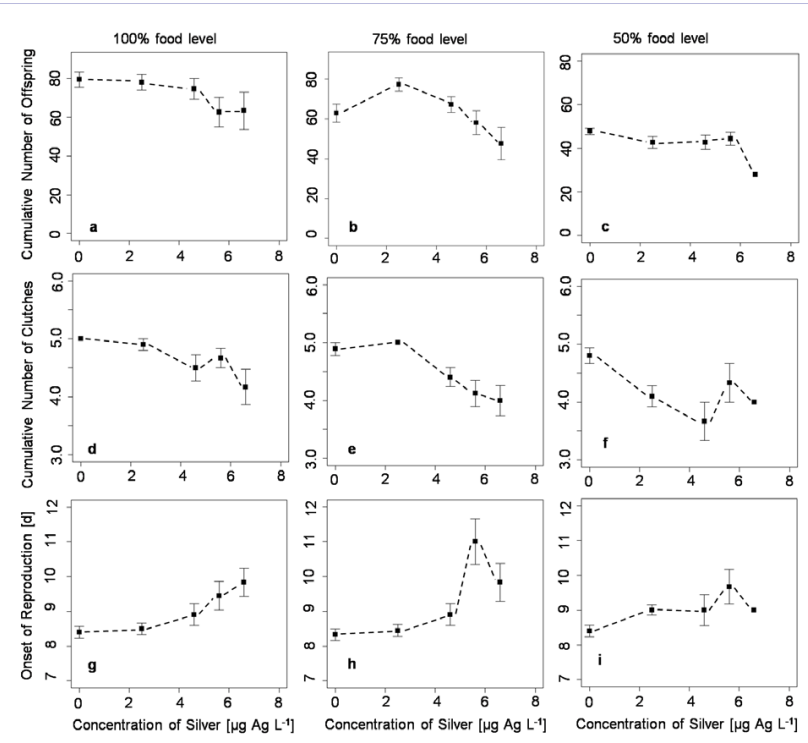

Figure 1: Reproductive effects of AgNP exposure in relation to silver concentration and food level. a) cumulative number of neonates in the standard food treatment, b) cumulative number of neonates in the $75 \%$ food treatment, c) cumulative number of neonates in the $50 \%$ food treatment, d) cumulative number of clutches in the standard food treatment, e) cumulative number of clutches in the $75 \%$ food treatment, f) cumulative number of clutches in the $50 \%$ food treatment, g) onset of reproduction in the standard food treatment, h) onset of reproduction in the $75 \%$ food treatment, i) onset of reproduction in the $50 \%$ food treatment. All values are given as mean values and standard errors (n: according to survival, Table 3 ).
Table 2: Overview of AgNP effects for all investigated endpoints in the chronic test, Food effects are presented in the supporting information (SI, Table S8). AgNP effects are given as NOEC and LOEC compared to

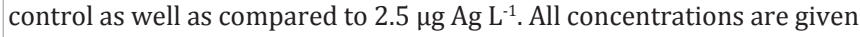
as $\mu \mathrm{g} \mathrm{Ag} \mathrm{L}^{-1}$. The level used for significance was $p<0.05$ and all results rose from post-hoc analysis of ANOVA or Kruskal-Wallis tests (SI, Table S1-S6).

\begin{tabular}{|c|c|c|c|c|c|}
\hline \multirow[t]{2}{*}{ Endpoint } & \multirow[t]{2}{*}{$\begin{array}{l}\text { Food } \\
\text { regime }\end{array}$} & NOEC & LOEC & NOEC & LOEC \\
\hline & & \multicolumn{2}{|c|}{ compared to control } & \multicolumn{2}{|c|}{$\begin{array}{l}\text { compared to } 2.5 \mu \mathrm{g} \\
\operatorname{Ag~L}^{-1}\end{array}$} \\
\hline \multirow{3}{*}{$\begin{array}{l}\text { Cumulative } \\
\text { Number of } \\
\text { Neonates }\end{array}$} & $100 \%$ & 6.6 & $>c_{\max }$ & & \\
\hline & $75 \%$ & 6.6 & $>c_{\max }$ & 4.6 & 5.6 \\
\hline & $50 \%$ & 6.6 & $>c_{\max }$ & & \\
\hline \multirow{3}{*}{$\begin{array}{l}\text { Cumulative } \\
\text { Number of } \\
\text { Clutches }\end{array}$} & $100 \%$ & 6.6 & $>c_{\text {max }}$ & & \\
\hline & $75 \%$ & 6.6 & $>c_{\max }$ & 5.6 & 6.6 \\
\hline & $50 \%$ & 2.5 & 4.6 & & \\
\hline \multirow{3}{*}{$\begin{array}{l}\text { Mean } \\
\text { Neonates per } \\
\text { Clutch }\end{array}$} & $100 \%$ & 6.6 & $>c_{\max }$ & & \\
\hline & $75 \%$ & 6.6 & $>c_{\max }$ & & \\
\hline & $50 \%$ & 6.6 & $>c_{\max }$ & & \\
\hline \multirow{3}{*}{$\begin{array}{l}\text { Onset of } \\
\text { Reproduction } \\
\text { [days] }\end{array}$} & $100 \%$ & 5.6 & 6.6 & & \\
\hline & $75 \%$ & 4.6 & 5.6 & & \\
\hline & $50 \%$ & 4.6 & 5.6 & & \\
\hline \multirow{3}{*}{ Size $[\mathrm{mm}]$} & $100 \%$ & 6.6 & $>c_{\max }$ & 4.6 & 5.6 \\
\hline & $75 \%$ & 6.6 & $>c_{\max }$ & & \\
\hline & $50 \%$ & 6.6 & $>c_{\max }$ & & \\
\hline \multirow{3}{*}{$\begin{array}{l}\text { Cumulative } \\
\text { Number of } \\
\text { Molts }\end{array}$} & $100 \%$ & 6.6 & $>c_{\text {max }}$ & & \\
\hline & $75 \%$ & 6.6 & $>c_{\max }$ & & \\
\hline & $50 \%$ & 6.6 & $>c_{\max }$ & & \\
\hline \multirow{3}{*}{ Mortality } & $100 \%$ & 5.6 & 6.6 & & \\
\hline & $75 \%$ & NA & NA & & \\
\hline & $50 \%$ & 5.6 & 6.6 & & \\
\hline
\end{tabular}

Table 3: Mortality at the end of the chronic Daphnia test in relation to AgNP concentration and food level $(n=10)$.

\begin{tabular}{|l|l|l|}
\hline Food Level & $\begin{array}{l}\text { Silver Concentration } \\
{\left[\mu \mathbf{A g ~ L}^{-1} \text { ] }\right.}\end{array}$ & Mortality [\%] \\
\hline $100 \%$ & Control & 0 \\
\hline & 2.5 & 0 \\
\hline & 4.6 & 0 \\
\hline & 5.6 & 10 \\
\hline $75 \% \mathrm{~V}$ & 6.6 & 40 \\
\hline & Control & 0 \\
\hline & 2.5 & 10 \\
\hline & 4.6 & 0 \\
\hline & 5.6 & 20 \\
\hline $50 \%$ & 6.6 & 40 \\
\hline & Control & 0 \\
\hline & 2.5 & 0 \\
\hline & 4.6 & 40 \\
\hline & 5.6 & 40 \\
\hline & 6.6 & 90 \\
\hline & & \\
\hline & & 40 \\
\hline
\end{tabular}


reproduction rendering mortality the most sensitive endpoint under standard conditions. The highest relative decrease of reproductive endpoints was observed for cumulative number of neonates (about 21\%).

\section{Influence of food reduction on AgNP toxicity}

Overall, the results of the $75 \%$ food level were comparable to the results of the standard food treatment, but the observed effects were less clear: only onset of reproduction had a true LOEC value, and cumulative number of neonates and number of clutches showed significant decreases compared to $2.5 \mu \mathrm{g} \mathrm{Ag} \mathrm{\textrm {L } ^ { - 1 }}$ (Table 2, Figure 1).

Still, the LOEC for onset of reproduction was lower than the one observed in the standard food treatment, rendering this endpoint the most sensitive one at this food level instead of mortality. Still, mortality had the highest relative change compared to the corresponding control (44\%).

When the food level was further reduced to $50 \%$, number of clutches and the onset of reproduction had decreasing LOECs compared to the standard food level (Table 2). This decrease was more pronounced for cumulative number of clutches (Figure 1b, Table 2), but the observed toxicity decreased slightly at AgNP concentrations above the LOEC. Mortality increased to $90 \%$ (Tables 2+3), while the LOEC values did not differ between food treatments (Table 2). This is making number of clutches the most sensitive endpoint according to LOECs, but the endpoint mortality having the highest impact on the test organisms. Onset of reproduction and cumulative number of clutches had only low relative decreases compared to the control (about 17\%).

\section{Discussion}

As could be expected, food reduction caused a decrease in growth and reproduction in terms of numbers of neonates. These

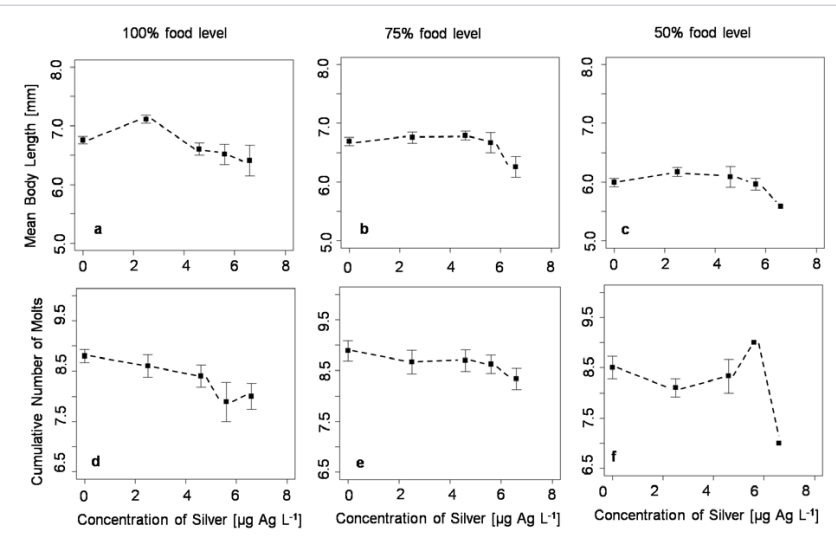

Figure 2: Body length at the end of the test and cumulative number of molts in relation to silver concentration and food level. a) body length in the standard food treatment, b) body length in the $75 \%$ treatment, c) body length in the $50 \%$ food treatment, d) cumulative number of molts in the standard food treatment, e) cumulative number of molts in the $75 \%$ food treatment, f) cumulative number of molts in the $50 \%$ food treatment. All values are given as mean values and standard variation (n: according to survival, Table 3 ).
Table 4: Overview on reproductive and lethal chronic toxicity of AgNP to $D$. magna in the literature. Only studies assessing the summarized endpoints were considered.

\begin{tabular}{|c|c|c|c|c|}
\hline Endpoint & $\begin{array}{l}\text { AgNP } \\
\text { coating }\end{array}$ & $\begin{array}{l}\text { Test } \\
\text { Concentration } \\
\text { range }[\mu \mathrm{g} \mathrm{Ag} \\
\left.\mathrm{L}^{-1}\right]\end{array}$ & $\begin{array}{l}\operatorname{LOEC}[\mu \mathrm{g} \\
\left.\operatorname{Ag~L}^{-1}\right]\end{array}$ & Reference \\
\hline \multirow[t]{7}{*}{$\begin{array}{l}\text { Cumulative } \\
\text { number of } \\
\text { offspring }\end{array}$} & citrate & $0-50$ & 40 & $\begin{array}{l}\text { Mackevica, et al. } \\
{[11]}\end{array}$ \\
\hline & & $0-60$ & 30 & Sakka, et al. [14] \\
\hline & PVP & $0-87$ & $29 />87^{*}$ & Blinova, et al. [9] \\
\hline & & $0-10$ & 2.5 & Völker, et al. [15] \\
\hline & carbonate & $0-500$ & 50 & Zhao, et al. [16] \\
\hline & alkane & $0-2.5$ & 1 & Ribeiro, et al. [12] \\
\hline & $\begin{array}{l}\text { detergent } \\
\text { stabilized }\end{array}$ & $0-60$ & $>60$ & Sakka, et al. [14] \\
\hline \multirow[t]{8}{*}{ Mortality } & citrate & $0-50$ & $>50$ & $\begin{array}{l}\text { Mackevica, et al. } \\
\text { [11] }\end{array}$ \\
\hline & & $0-60$ & 30 & Sakka, et al. [14] \\
\hline & PVP & $0-87$ & $50 />87^{*}$ & Blinova, et al. [9] \\
\hline & & $0-10$ & $>10$ & Völker, et al. [15] \\
\hline & uncoated & $0-10000$ & $>10000$ & Gaiser, et al. [10] \\
\hline & & $0-17.44$ & $\mathrm{EC}_{10}: 3.77$ & $\begin{array}{l}\text { Sakamoto, et al. } \\
\text { [13] }\end{array}$ \\
\hline & carbonate & $0-500$ & 500 & Zhao, et al. [16] \\
\hline & $\begin{array}{l}\text { detergent } \\
\text { stabilized }\end{array}$ & $0-60$ & $>60$ & Sakka, et al. [14] \\
\hline
\end{tabular}

*differences in results are related to the use of different natural waters for each set of chronic tests

results are in line with published literature on food quantity effects in several Daphnia species [20,22,28,30,31] that we did not observe a delay in reproduction, as has been reported elsewhere $[26,22,38]$ also for comparable amounts of food $(0.1$

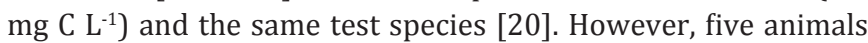
had been placed into the same test vessel in the cited study, so it is possible that the carbon quantity available for each single animal was further reduced. This would render the carbon concentration in our study higher than the reported threshold for a delay in reproduction for D. magna.

Using standard food conditions, chronic AgNP exposure caused an increase in mortality, a delay in reproduction and reduction of number of neonates. The endpoints affected by AgNP vary between studies, but reduction of cumulative numbers of offspring is the endpoint most often affected by chronic AgNP exposure and also the one having the lowest LOEC from all studies (Table 4). However, in our study, only a general decrease was observed and a LOEC could not be determined.

A delay in reproduction has only been reported in one other study using citrate-coated AgNP [11], while chronic AgNP exposure had no such effect in two other experiments $[14,16]$.

Increased mortality due to chronic AgNP exposure has been reported for several kinds of AgNP (Table 4). The LOEC for 
mortality in our study is comparable to the result reported for uncoated AgNP [13] and lower than those of the other studies $[9,11,14,16]$.

While several studies report reduction of growth and/or molting as response to chronic AgNP exposure $[10,11,16]$, no such effect has been observed in our study. Overall, the used AgNP had a rather low reproductive effect, while the effect on survival was comparatively high.

In this context, it is important to note that the same AgNP was also used in another chronic test with D. Magna [14] where it did not cause significant negative effects to the test organisms compared to the controls. The main differences between these two experiments were the use of two different clones and caused by this different $\mathrm{pH}$ values. The later is most likely related to a change in AgNP behavior: while AgNP in the previous study were of stable agglomerate size for two days [14], the size of AgNP agglomerates increased to about $500 \mathrm{~nm}$ in the present study. To explain To explain these and the overall differences in chronic AgNP toxicity, systematic investigations on chronic toxicity and AgNP properties are needed to explain these differences between studies.

When the amount of food was reduced, mortality remained one of the most sensitive endpoints while the effect on number of neonates became less pronounced. However, the number of clutches became increasingly sensitive and showed the highest sensitivity (lowest LOEC) of all end points at the $50 \%$ food level. In the other study addressing the effect of food on AgNP toxicity, an increase in food quantity reduced the effect on reproduction and survival [11], supporting an interaction between AgNP effects and food supply. This is of special interest, as uptake by ingestion is an important pathway in AgNP accumulation [39] and may be important for the intensity of toxic effects [14]. The observed reduction of AgNP toxicity at higher food concentrations can thus be explained either by reduction of AgNP uptake due to a "dilution effect" of the additional algae present in the medium or by the additional energy provided by higher food quantities that allow higher levels of self-maintenance.

The measurement of silver body burdens in the present study suggests a reduced uptake of silver at higher food quantities, but the values measured at both reduced food quantities were similar while the toxicity was clearly different. This indicates that despite a possible dilution effect by additional algae not attached to AgNP at the standard food level, the toxicity of AgNP is affected by the available energy in terms of carbon.

The increase of AgNP toxicity at low food levels shows that natural D. magna populations are most sensitive to AgNP when algae concentrations in lakes are low. A strong reduction in phytoplankton numbers is mainly observed during the spring clear water phase when zooplankton density is high [23]. Introduction of AgNP during this phase of the year may increase zooplankton mortality to a large extent and elongate time to recover. However, the relation between algae and zooplankton populations is affected by numerous other factors such as temperature and presence/absence of predators, and even species-related differences in growth parameters $[25,40]$. Thus, modeling the obtained results using a number of environmental parameters is required to get a clear picture on the environmental effects of AgNP. To our knowledge, only one model addresses the effect of AgNP in a freshwater environment [41], In this study, however, AgNP toxcity affected only the first trophic level (algae), so that effects on zooplankton were based on algal abundances only. Due to the comparably high sensitivity of Daphnia towards AgNP [7] and their important role in limnic zooplankton grazer communities [23], the direct effects of AgNP on zooplankton are likely to affect natural populations in a similar manner as AgNP effects on algae.

\section{Conclusion}

Toxicity in the present study was detectable at comparably low levels and further increased when food was provided in low quantities. Even though endpoints differed in their response to food reduction, reproduction was further reduced by AgNP exposure at low food levels. In addition, mortality increased strongly at low food levels further adding to overall toxicity. Beside the higher levels of toxicity, NOEC and LOEC values did only decrease for two endpoints (start of reproduction and number of clutches). Thus, for risk assessment, standard food levels can be considered to be protective, while fate models may require more information on the relation between food level, uptake and toxic effect to assess the consequence of increased toxic levels.

In addition, our study supports the conclusion that environmental concentrations slightly above the expected range of $n g \mathrm{~L}^{-1}$ can pose a risk to Daphnia populations in the environment.

\section{Acknowledgements}

AgNP (OECD material NM-300K) were provided by the UMSICHT project (BMBF 03X0091).

\section{References}

1. The Nanodatabase, http://nanodb.dk/ , last assessed: March 2016.

2. Benn TM, Westerhoff P. Nanoparticle Silver Released into Water from Commercially Available Sock Fabrics. Environ Sci Technol. 2008;42(11):4133-9.

3. Geranio L, Heuberger M, Nowack B. The Behavior of Silver Nanotextiles during Washing. Environ Sci Technol. 2009;43(21):8113-8. doi: 10.1021/es9018332.

4. Gottschalk F, Sun T, Nowack B. Environmental concentrations of engineered nanomaterials: Review of modeling and analytical studies. Environ Pollut. 2013;181:287-300. doi: 10.1016/j. envpol.2013.06.003.

5. Kaegi R, Voegelin A, Sinnet B, Zuleeg S, Hagendorfer H, Burkhardt M, et al. Behavior of Metallic Silver Nanoparticles in a Pilot Wastewater Treatment Plant. Environ. Sci. Technol. 2011;45(9):3902-3908.

6. Wigger H, Hackmann S, Zimmermann T, Köser J, Thöming J, von Gleich A. Influences of use activities and waste management on environmental releases of engineered nanomaterials. Sci Total Environ. 2015;535:160-71. doi: 10.1016/j.scitotenv.2015.02.042. 
7. Fabrega J, Luoma SN, Tyler CR, Galloway TS, Lead JR. Silver nanoparticles: Behaviour and effects in the aquatic environment Environ Int. 2011;37(2):517-31. doi: 10.1016/j.envint.2010.10.012.

8. Sharma VK, Siskova KM, Zboril R, Gardea-Torresdey JL. Organic-coated silver nanoparticles in biological and environmental conditions: Fate, stability and toxicity. Adv Colloid Interface Sci. 2014;204:15-34. doi: 10.1016/j.cis.2013.12.002

9. Blinova I, Niskanen J, Kajankari P, Kanarbik L, Käkinen A, Tenhu H, et al. Toxicity of two types of silver nanoparticles to aquatic crustaceans Daphnia magna and Thamnocephalus platyurus. Environ Sci Pollut Res Int. 2013;20(5):3456-63. doi: 10.1007/s11356-012-1290-5.

10. Gaiser BK, Biswas A, Rosenkranz P, Jepson MA, Lead JR, Stone V, et al. Effects of silver and cerium dioxide micro- and nano-sized particles on Daphnia magna. J Environ Monit. 2011;13(5):1227-35. doi: 10.1039/ c1em10060b.

11. Mackevica A, Skjolding LM, Gergs A, Palmqvist A, Baun A. Chronic toxicity of silver nanoparticles to Daphnia magna under different feeding conditions. Aquatic Toxicology. 2015;161:10-16.

12. Ribeiro F, Gallego-Urrea JA, Jurkschat K, Crossley A, Hassellöv M, Taylor C, et al. Silver nanoparticles and silver nitrate induce high toxicity to Pseudokirchneriella subcapitata, Daphnia magna and Danio rerio. Sci Total Environ. 2014;466-467:232-41. doi: 10.1016/j. scitotenv.2013.06.101.

13. Sakamoto M, Ha JY, Yoneshima S, Kataoka C, Tatsuta H, Kashiwada S. Free Silver Ion as the Main Cause of Acute and Chronic Toxicity of Silver Nanoparticles to Cladocerans. Arch Environ Contam Toxicol. 2015;68(3):500-9. doi: 10.1007/s00244-014-0091-x.

14. Sakka Y, Skjolding LM, Mackevica A, Filser J, Baun A. Behavior and chronic toxicity of two differently stabilized silver nanoparticles to Daphnia magna. Aquatic Toxicology. 2016;177:526-535.

15. Völker C, Boedicker C, Daubenthaler J, Oetken M, Oehlmann J. Comparative Toxicity Assessment of Nanosilver on Three Daphnia Species in Acute, Chronic and Multi-Generation Experiments. PLoS One. 2013;8(10):e75026. doi: 10.1371/journal.pone.0075026.

16. Zhao CM, Wang WX. Comparison of acute and chronic toxicity of silver nanoparticles and silver nitrate to Daphnia magna. Environ Toxicol Chem. 2011;30(4):885-92. doi: 10.1002/etc.451.

17. Levard C, Hotze EM, Lowry GV, Brown GE Jr. Environmental Transformations of Silver Nanoparticles: Impact on Stability and Toxicity. Environ Sci Technol. 2012;46(13):6900-14. doi: 10.1021/ es2037405

18. Lam IKS, Wang WX. Accumulation and elimination of aqueous and dietary silver in Daphnia magna. Chemosphere. 2006;64:26-35

19. Boersma M. Offspring size and parental fitness in Daphnia magna Evolutionary Ecology. 1997;11(4):439-450.

20. Giebelhausen B, Lampert W. Temperature reaction norms of Daphnia magna: the effect of food concentration. Freshw. Biol. 2001;46(3):281289.

21. Gliwicz ZM, Ghilarov A, Pijanowska J. Food and predation as major factors limiting two natural populations of Daphnia cucullata Sars. Hydrobiologia. 1981;80(3):205-218.

22. Guisande C, Gliwicz ZM. Egg size and clutch size in two Daphnia species grown at different food levels. Journal of Plankton Research. 1992;14(7):997-1007.

23. Lampert W, Fleckner W, Rai H, Taylor BE. Phytoplankton control by grazing zooplankton: A study on the spring clear-water phase. Limnol. Oceanogr. 1986;31(3):478-490.

24. McCauley E, Murdoch WW, Nisbet RM, Gurney WSC. The Physiological
Ecology of Daphnia: Development of a Model of Growth and Reproduction. Ecology. 1990;71(2):703-715.

25. Rinke K, Vijverberg J. A model approach to evaluate the effect of temperature and food concentration on individual life-history and population dynamics of Daphnia. Ecological Modelling. 2005;186(3):326-344.

26. Boersma M, Vijverberg J. Resource depression in Daphnia galeata, Daphnia cucullata and their interspecific hybrid: life history consequences. Journal of Plankton Research. 1994;16(12):17411758.

27. Michael L. The Life History Consequences of Resource Depression in Daphnia pulex. Ecology. 1989;70(1):246-256.

28.Vijverberg J. The effect of food quantity and quality on the growth, birth-rate and longevity of Daphnia hyalina Leydig. Hydrobiologia. 1976;51(2):99-108.

29. Boersma M, Vijverberg J. Seasonal variations in the condition of two Daphnia species and their hybrid in a eutrophic lake: evidence for food limitation. Journal of Plankton Research. 1994;16(12):1793-1809.

30. Lampert W. A field study on the dependence of the fecundity of Daphnia spec. on food concentration. Oecologia. 1978;36(3):363-369.

31. Müller-Navarra D, Lampert W. Seasonal patterns of food limitation in Daphnia galeata: separating food quantity and food quality effects. Journal of Plankton Research. 1996;18(7):1137-1157.

32. Enserink L, de la Haye M, Maas H. Reproductive strategy of Daphnia magna: implications for chronic toxicity tests. Aquatic Toxicology. 1993;25(1-2):111-124.

33. Rinke K, Petzoldt T. Modelling the effects of temperature and food on individual growth and reproduction of Daphnia and their consequences on the population level. Limnologica - Ecology and Management of Inland Waters. 2003;33(4):293-304.

34.Vigano L. Reproductive Strategy of Daphnia magna and Toxicity of Organic Compounds. Water Research. 1993;27(5):903-909.

35. Hensel A, Rischer M, Di Stefano D, Behr I, Wolf-Heuss E. Full chromatographic characterization of nonionic surfactant polyoxyethylene gylcerol trioleate. Pharmaceutica Acta Helvetiae. 1996;72(3):185-189.

36. Organisation for Economic Co-operation and Development, Test No. 211. Daphnia magna Reproduction Test. OECD guidelines for Testing of Chemicals. 1998.

37. R Development Core Team, 2016 (Available from 2008). R: A language and environment for statistical computing. $\mathrm{R}$ Foundation for Statistical Computing, Vienna, Austria. ISBN 3-900051-07-0, URL http://www.R-project.org

38. McCauley E, Murdoch WW, Nisbet RM. Growth, Reproduction, and Mortality of Daphnia pulex Leydig: Life at Low Food. British Ecological Society. 1990;4(4):505-514.

39. Zhao CM, Wang WX. Biokinetic Uptake and Efflux of Silver Nanoparticles in Daphnia magna. Environ Sci Technol. 2010;44(19):7699-704. doi: 10.1021/es101484s.

40. McCauley E, Murdoch WW. Cyclic and Stable Populations: Plankton as Paradigm. Am. Nat. 1987;129(1):97-121.

41. Rana S, Samanta S, Bhattacharya S, Al-Khaled K, Goswami A, Chattopadhyay J. The effect of nanoparticles on plankton dynamics: A mathematical model. Biosystems. 2015;127:28-41. doi: 10.1016/j. biosystems.2014.11.003 